\title{
Thermo-Kinetic Investigation of Comparative Ligand Effect on Cysteine Iron Redox Reaction
}

\author{
Masood Ahmad Rizvi, ${ }^{\mathrm{a}, *}$ Norio Teshima, ${ }^{\mathrm{b}}$ Syed Raashid Maqsood, ${ }^{\mathrm{a}}$ \\ Showket Ahmad Akhoon, ${ }^{a}$ and Ghulam Mustafa Peerzada ${ }^{a}$ \\ ${ }^{a}$ University of Kashmir, Department of Chemistry, Hazratbal Srinagar, 190006, J\&K, India \\ ${ }^{\mathrm{b}}$ Aichi Institute of Technology, Department of Applied Chemistry, 1247 Yachigusa, \\ Yakusa-cho, Toyota 470-0392, Japan
}

RECEIVED MAY 14, 2014; REVISED DECEMBER 11, 2014; ACCEPTED FEBRUARY 9, 2015

\begin{abstract}
Transition metal ions in their free state bring unwanted biological oxidations generating oxidative stress. The ligand modulated redox potential can be indispensable in prevention of such oxidative stress by blocking the redundant bio-redox reactions. In this study we investigated the comparative ligand effect on the thermo-kinetic aspects of biologically important cysteine iron (III) redox reaction using spectrophotometric and potentiometric methods. The results were corroborated with the complexation effect on redox potential of iron(III)-iron(II) redox couple. The selected ligands were found to increase the rate of cysteine iron (III) redox reaction in proportion to their stability of iron (II) complex (EDTA $<$ terpy $<$ bipy < phen). A kinetic profile and the catalytic role of copper (II) ions by means of redox shuttle mechanism for the cysteine iron (III) redox reaction in presence of 1,10-phenanthroline (phen) ligand is also reported.
\end{abstract}

Keywords: ligand effect, bio-redox, cysteine, redox shuttle, reactive oxygen species (ROS)

\section{INTRODUCTION}

The flexibility of spin states, divergence in hard soft nature of oxidation states, modulation of reduction potential, assorted compound stabilities and diverse structural options bestow iron its special characteristics befitting biosystems. ${ }^{1}$ Nevertheless in biosystems, iron can be a double-edged sword, when coordinated to its natural binding sites it performs the desired job and on de-compartmentalization it brings the deleterious function. $^{2,3}$ In the domain of biological oxygen chemistry iron presents a significant paradox, it is vital for cellular functions yet it can also catalyze the harmful oxidation of biomolecules (DNA, Proteins and Lipids). ${ }^{4}$ The iron mediated oxidation of bio-molecules is proposed to occur by the generation of reactive oxygen species like the hydroxyl radical. ${ }^{4}$ The amino acid cysteine is considered to be the primary target for in vivo oxidation by free iron (III) ions. The biological significance of cysteine iron redox reactions has made this reaction a subject of several studies in recent years. ${ }^{5-11}$ Selective chelation can modify the potential of iron system and prevent it from participating in the catalytic processes producing reactive oxygen species, (ROS), for this reason designed chelation can block the unwanted biological oxidations. ${ }^{11}$

The ligand environments modulate the potential of the iron redox couple and depending upon the type of modulation some ligand systems speed up while others quench the reaction. The iron complexes of the latter ligands can be considered as indirect antioxidants which avert the generation of ROS rather than removing the ROS species like the common antioxidants. ${ }^{12}$ As an extension to our previous studies of complexation effect on iron redox couple. ${ }^{13,14}$ We attempted to investigate the coordination coupled electron transfer between cysteine and iron (III) complexes to highlight the ligand effect on the thermokinetic aspects of iron (III) cysteine redox reaction in acid aqueous system. A comparative propensity of two closely related $N, N$-bidentate pi $(\pi)$ acceptor ligands for the cysteine iron electron transfer was kinetically investigated and plausibly explained using quantum chemical descriptors. An interesting observation about the catalytic role of copper (II) ions in the coordination inspired electron transfer between iron and cysteine by means of a redox shuttle mechanism is also reported.

\footnotetext{
* Author to whom correspondence should be addressed. (E-mail: masoodku2@gmail.com)
} 


\section{EXPERIMENTAL}

\section{Materials}

Analytical grade ammonium iron(III) sulphate, cysteine hydrochloride, 1,10-phenanthroline (phen), EDTA disodium salt, 2',2-bipyridyl (bipy), terpyridine (terpy) and copper (II) sulphate were purchased from Merck India and used as such without further purification. In order to prevent iron (III) hydrolysis and enhance the solubilities of phen, bipy and terpy, the solutions were prepared and desired dilutions were also done with acidified water $\left(1 \times 10^{-3} \mathrm{M} \mathrm{H}_{2} \mathrm{SO}_{4}\right)$.

\section{Instrument and Physical Measurements}

Spectrophotometric measurements were carried on Shimadzu 1650 UV-visible spectrophotometer with thermostatic control. Potentiometric measurements were carried on Eutech PC5500 ion analyzer over a thermostatic magnetic stirrer. The geometries of Phen and Bipy ligands were optimized with the Gaussian 03 quantum chemistry package using Becke's three parameter hybrid functional (B3LYP) and the 6-311G (d,p) ++ basis set.

\section{General Procedure}

The thermodynamic studies of ligand effect on iron(III) cysteine redox reaction were done through potentiometric titrations of iron(III) complexes of selected ligands with $\left(1 \times 10^{-2} \mathrm{~mol} \mathrm{~L}^{-1}\right)$ cysteine. In a typical potentiometric experiment a total of $50 \mathrm{~mL}$ analyte was prepared from $15 \mathrm{~mL}$ iron(III) solution to which $20 \mathrm{~mL}$ of acetate buffer ( $\mathrm{pH} 4$ ) was added followed by $5 \mathrm{~mL}$ of selected ligand solution (maintaining iron-ligand molar ratio for octahedral composition) and diluting to $50 \mathrm{~mL}$ with distilled water. The $20 \mathrm{~mL}$ of this analyte solution was potentiometrically estimated with $\left(1 \times 10^{-2} \mathrm{~mol} \mathrm{~L}^{-1}\right)$ cysteine (Figure 1). The analytical details of the iron(III) phen system used to study the effect of phen iron(III) molar ratio are as described in Table 1.

The kinetic analysis of ligand effect on iron(III) cysteine redox reaction were done spectrophotometerically using $\left(1 \times 10^{-3} \mathrm{~mol} \mathrm{~L}^{-1}\right)$ solution each of

Table 1. Analytical details of iron(III) phen system $50 \mathrm{~mL}$ flasks

\begin{tabular}{ccccc}
\hline Flask & $\begin{array}{c}\text { Iron(III) } \\
\left(1 \times 10^{-2} \mathrm{M}\right) \\
/ \mathrm{mL}\end{array}$ & $\begin{array}{c}\text { Acetate } \\
\text { buffer } \\
\mathrm{pH} 4 / \mathrm{mL}\end{array}$ & $\begin{array}{c}\text { Phen ligand } \\
\left(1 \times 10^{-1} \mathrm{M}\right) \\
/ \mathrm{mL}\end{array}$ & $\begin{array}{c}\text { Distilled } \\
\text { water } / \\
\mathrm{mL}\end{array}$ \\
\hline 1 & 15.0 & 20.0 & 5.0 & 10.0 \\
2 & 15.0 & 20.0 & 4.0 & 11.0 \\
3 & 15.0 & 20.0 & 3.5 & 11.5 \\
4 & 15.0 & 20.0 & 3.0 & 12.0 \\
5 & 15.0 & 20.0 & 2.5 & 12.5 \\
\hline
\end{tabular}

iron(III) sulphate and cysteine and $\left(1 \times 10^{-2} \mathrm{~mol} \mathrm{~L}^{-1}\right)$ ligand solution. The catalytic role was worked out using $\left(1 \times 10^{-4} \mathrm{~mol} \mathrm{~L}^{-1}\right)$ copper(II) sulphate. The effect of various parameters like temperature and concentration ratio's on iron (III) cysteine redox reaction kinetics were also studied taking care of all the necessary experimental precautions. In a typical kinetic experiment $1.0 \mathrm{~mL}$ each of cysteine and the ligand followed by $1.0 \mathrm{~mL}$ iron(III) sulphate as reaction starter was added. The kinetics was monitored at $\lambda_{\max }(265 \mathrm{~nm})$ of cysteine in case of comparative ligand study. The detailed kinetics of iron(III) cysteine in presence of phen and bipy ligand was also monitored at $\lambda_{\max }$ of 510 and $520 \mathrm{~nm}$ corresponding to $\left[\mathrm{Fe}(\text { phen })_{3}\right]^{2+}$ and $\left[\mathrm{Fe}(\text { bipy })_{3}\right]^{2+}$ respectively. To study copper effect $0.5 \mathrm{~mL}$ of copper(II) sulphate was added to the cysteine ligand (phen, bipy) mixture before adding $1 \mathrm{~mL}$ of iron(III) as reaction starter.

\section{RESULTS AND DISCUSSION}

The concern of iron induced oxidative stress and neurodisorders ${ }^{15}$ stimulate interest in the design of modernday antioxidants which actively block generation of ROS and not simply prevent the damage by ROS. The iron prompted oxidative damage to proteins primarily involves the redox interaction between iron(III) and the cysteine amino acid in proteins. ${ }^{16}$ The reaction between cysteine and iron(III) is an overall one-electron-transfer process that involves the reduction of iron(III) to iron(II) with the concomitant oxidation of cysteine to cystine. In this work we highlight the ligand effect on the thermo-kinetic aspects of coordination coupled electron transfer between iron(III) and cysteine. The aqueous phase electron transfer between iron(III) and cysteine although thermodynamically feasible is very slow at room temperature. In the potentiometric

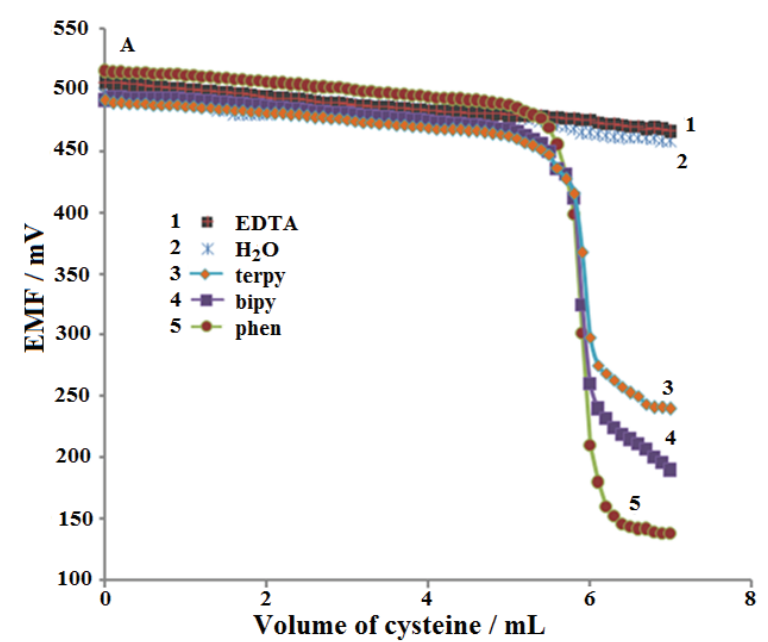

Figure 1. Potentiometric response of iron(III) cysteine redox reaction in presence of selected ligands. 


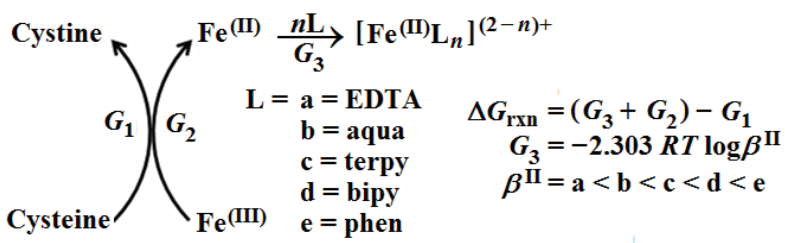

Scheme 1. Coordination coupled electron transfer between iron(III) and cysteine.

estimation of iron(III) with cysteine, a clear potential jump at the equivalence point is obtained only in presence of ligand and when performed around $50{ }^{\circ} \mathrm{C}$. The potential change in the vicinity of the inflection point was found to be in proportion with the stability of iron(II) complex with the selected ligands (Figure 1). The distinctive influence of studied ligands on potentiometric behavior of the iron(III) cysteine redox reaction can be explained by coordination coupled electron transfer $^{17}$ (Scheme1).

In presence of the ligand, the free energy of complexation step $G_{3}$ adds to the free energy of electron transfer step $G_{2}$, giving an overall free energy change of reaction as $\left(G_{3}+G_{2}\right)-G_{1}$, compared to $G_{2}-G_{1}$ in absence of any ligand. The strength of iron(II) complex ( $\beta^{\mathrm{II}}$ value) contributes to the $G_{3}$ component of the overall free energy change of the reaction. The higher the iron(II) formation constant of the ligand, higher is its contribution to $G_{3}$ and higher free energy change of the reaction (larger change in EMF) at equivalence point is observed. The identification of the active iron species for this redox reaction was envisaged from the shifting of the potentiometric inflection point in accordance to the proportion of iron(II) phenanthroline and not the total iron(III) in the reaction mixture (Figure 2).

In addition to the modified thermodynamics, the kinetic behavior of the said reaction depicts significant

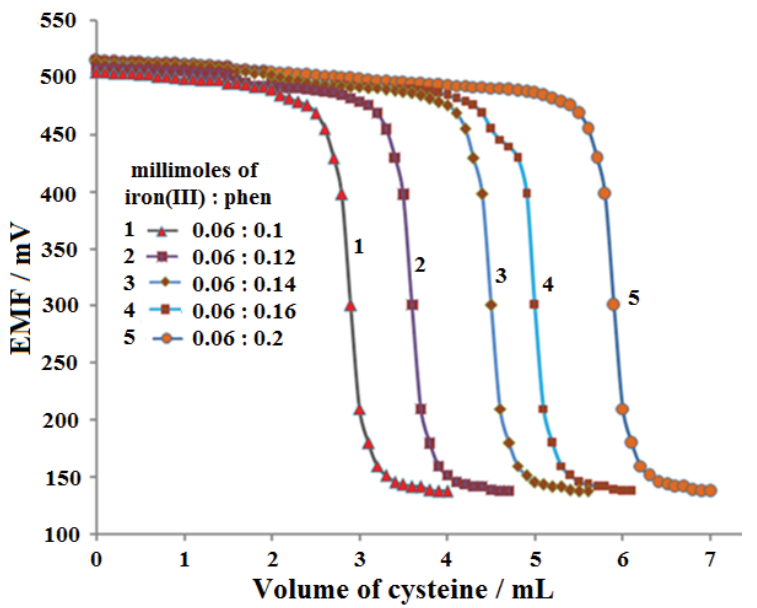

Figure 2. Effect of iron(III) phenanthroline molar ratio on potentiometeric response of iron(III) cysteine redox reaction. difference in absence and in presence of ligands. The time dependant absorbance measurements at $\lambda_{\max }=$ $265 \mathrm{~nm}$ corresponding to cysteine reveal a very slow rate of $\mathrm{Fe}(\mathrm{III})$ induced cysteine oxidation to cystine. Nevertheless the 400-500 fold reaction rate acceleration was observed in presence of selected ligands phen and bipy and practically no reaction kinetics was noticeable with EDTA as a ligand. The varying slope of curves a, $\mathrm{b}, \mathrm{c}$ and $\mathrm{d}$ illustrate the escalating effect of selected ligands on cysteine iron(III) electron transfer (Figure 3 ). The potentiometric response and kinetic profile of the iron(III) complexes towards cysteine oxidation depicted in Figure 3 can be explained by ligand modulation of iron redox potential by relative stabilization of iron oxidation states in accordance to Equation $1 .^{13}$

$$
E_{\text {complex }}=E_{\text {aqua }}-59.16 \log \frac{\beta^{\text {III }}}{\beta^{\text {II }}}
$$

The relatively higher stabilization of iron(II) by ligands (phen and bipy) give $\beta^{\mathrm{III}} / \beta^{\mathrm{II}}<1$ and therefore a higher reduction potential relative to the aqueous state, while EDTA stabilizes iron(III) relatively more than iron(II) giving give $\beta^{\mathrm{III}} / \beta^{\mathrm{II}}>1$ and thus a lower reduction potential relative to the aqueous state. ${ }^{18}$ The higher reduction potential of iron in presence of 1,10phenanthroline and bipyridyl ${ }^{19}$ increases its tendency to oxidize cysteine while its lower reduction potential in presence of EDTA prevents the oxidation of cysteine by iron(III). ${ }^{20}$ Hence ligands like EDTA which stabilize iron(III) can be effective in preventing the unwanted biological oxidation of iron(III). Another interesting observation of the kinetic profile (Figure 3) lies in the comparative propensity of two closely-related $\mathrm{N}, \mathrm{N}$ bidentate ligands phen and bipy towards cysteine

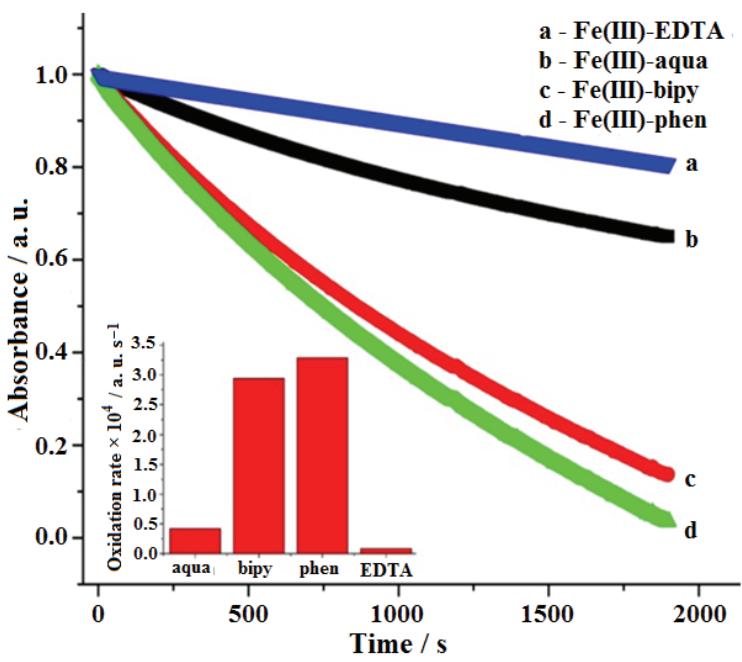

Figure 3. Comparative ligand effect on kinetics of iron(III) cysteine redox reaction monitored at $\lambda_{\max }$ of cysteine $(265 \mathrm{~nm})$. 

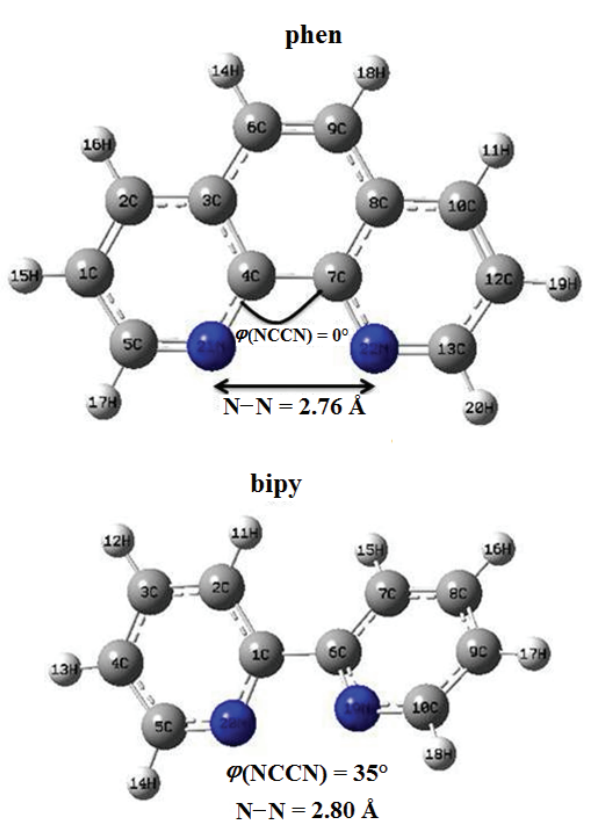

Figure 4. Comparison of ligand preorganization from optimized structures of phen and bipy. $(\varphi(\mathrm{NCCN})$ designates the dihedral angel at the chelating site of the ligands).

iron(III) redox reaction. The relatively faster kinetics of phen compared to bipy further strengthens the proposed significance of iron(II) stabilization in the thermokinetic behavior of cysteine iron(III) redox reaction. Raashid et.al. recently reported ${ }^{21}$ using density functional theory (DFT) calculations that in case of two $N, N$ bidentate ligands phen and bipy the difference in the iron(II) stabilization is due to the steric factors. The spatial arrangement of donor atoms in optimized structures of the two ligands reveal that the relatively shorter $\mathrm{N}-\mathrm{N}$ distance and steric restriction over rotation about $\mathrm{NC}-\mathrm{CN}$ bond in phen (dihedral angle $\varphi(\mathrm{NCCN})=0^{\circ}$ ) results in an entropically favoured chelate binding of phen compared to bipy (dihedral angle $\varphi(\mathrm{NCCN})=35^{\circ}$ )

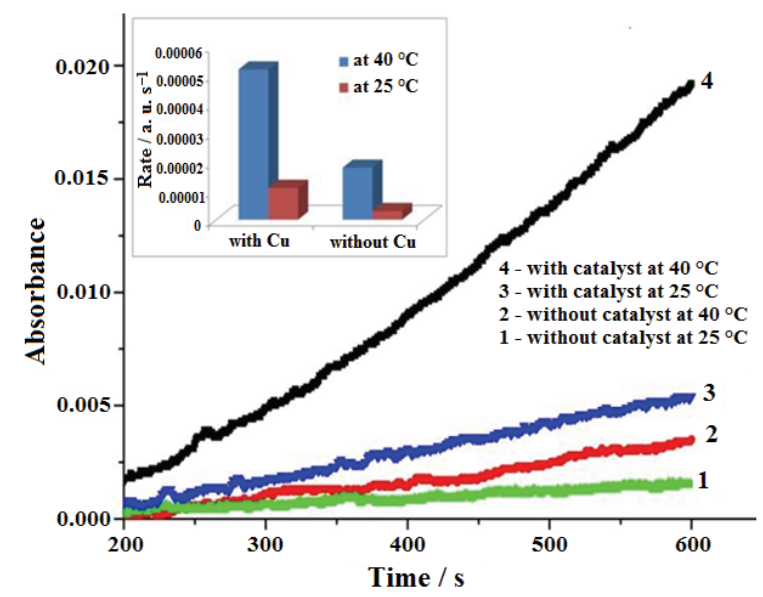

Figure 5. Effect of copper(II) ions on the kinetics of iron(III) cysteine redox transfer at two temperatures.

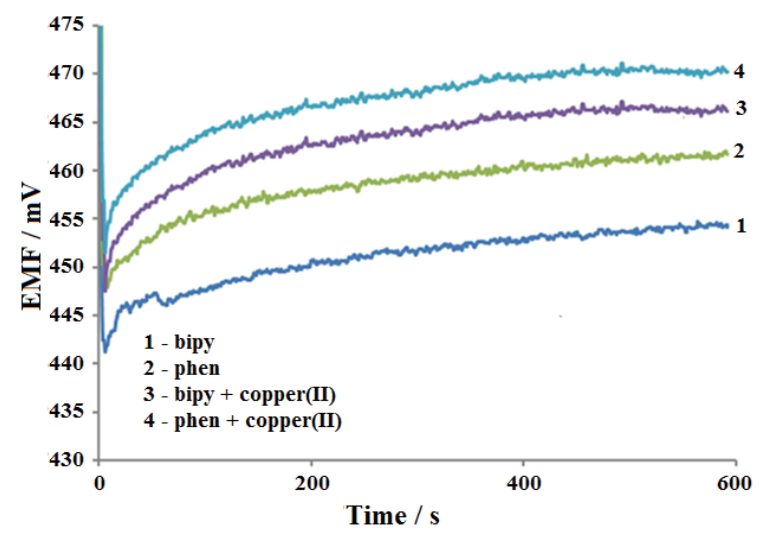

Figure 6. EMF changes with time for iron(III) cysteine redox reaction with and without copper(II) ions.

(Figure 4).The fused ring system in case of phen makes it effectively more pre-organized at the chelation site compared to bipy. Thus phen behaves as a better pi acceptor compared to bipy. ${ }^{22}$

\section{Effect of Copper(II) Ion on Redox Reaction}

Comparison of the redox potentials ${ }^{23}$ predict the ability of redox active copper(II) ion to influence cysteine iron(III) redox reaction. A survey of literature reports some $^{24-26}$ analytical estimations of copper(II) at sub ppb levels based on its influence on cysteine iron(III) redox reaction. However to the best of our searching ability we did not find a kinetic exploration of role of copper(II) in cysteine iron(III) redox reaction. Kinetic investigations of cysteine iron redox reaction using spectrophotometry and potentiometry depict an extraordinary enhancement in the reaction rate in presence of copper(II) ions (Figures 5 and 6). The modification in the kinetic behavior of the cysteine $\left[\mathrm{Fe}(\text { phen })_{3}\right]^{2+}$ redox reaction in presence of copper(II) ions predict the possibilities of a stoichiometric or catalytic role of copper(II) ions in the redox reaction. The stoichiometric role of

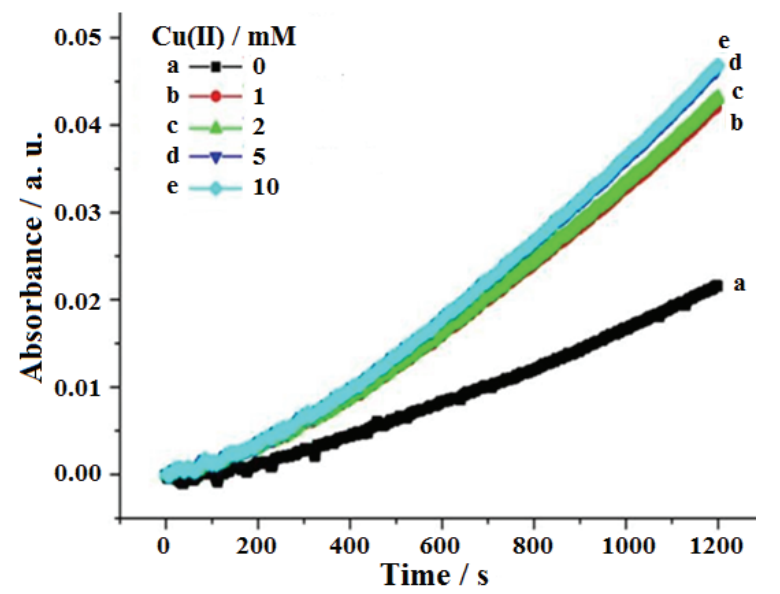

Figure 7. Effect of copper(II) ion concentration on kinetics of iron(III) cysteine redox reaction in presence of phen. 


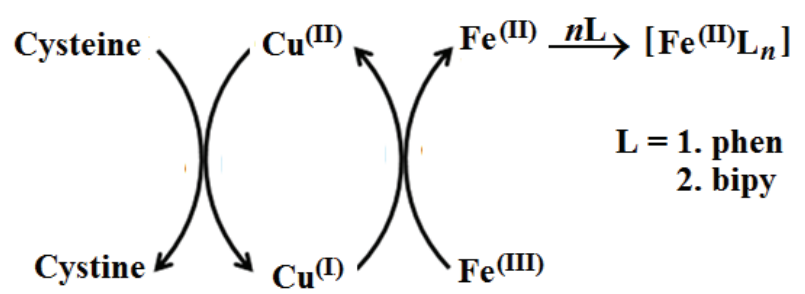

Scheme 2. Redox shuttle role of copper(II) ion.

copper(II) ions for the cysteine iron(III) redox reaction was eliminated by noting the effect of copper(II) concentration profile on the kinetics of the redox reaction. From the Figure 7 it is clear that an the initial addition of copper(II) ions enhance the rate of reaction appreciably however successive increase in copper(II) concentration does not show a prominent enhancement in the reaction rate suggesting a non stichiometeric or a catalytic role. The plausible pathway of the copper(II) catalysis which mainly permit the experimental observations and further supported by available redox potentials can be that of the redox shuttle ${ }^{27}$ (Schemes 2 and 3) where $E^{\circ^{\prime}}(-0.34 \mathrm{~V})$ is the formal redox potential of cysteine-cysteine redox couple under biological conditions. ${ }^{28}$ In the first step copper(II) oxidizes cysteine, the copper(I) generated in the process has two possible reaction paths, aqueous phase disproportionation or re-oxidation to copper(II). Obviously the thermodynamic feasibility decides the dominant reaction out of two competing reactivities. An equilibrium constant of $K=10^{10.45}$ (for re-oxidation reaction) can be calculated from the standard aqueous phase redox potentials of the copper(II)-copper(I) (0.16 V vs. NHE) and iron(III)iron(II) $\left(0.77 \mathrm{~V} v s\right.$. NHE). ${ }^{29}$ While as the equilibrium constant for $\mathrm{Cu}(\mathrm{I})$ disproportionation is $1.3 \times 10^{6}$ at $298 \mathrm{~K}^{30}$ Thus re-oxidation of copper(I) to copper(II) in presence of iron(III) is more favourable over

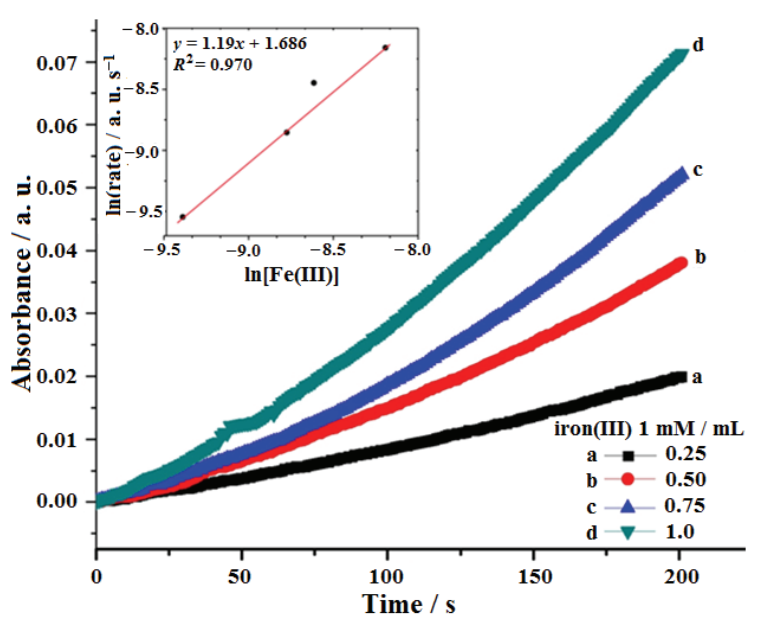

Figure 8. Pseudofirst order kinetics plot with respect to iron(III)

$$
\begin{aligned}
2 \text { Cysteine }+2 \mathrm{Cu}(\mathrm{II}) & \rightarrow \mathrm{Cystine}+2 \mathrm{Cu}(\mathrm{I}) & \{E=0.5 \mathrm{~V}(0.16-(-0.34))\} \\
\mathrm{Cu}(\mathrm{I})+\mathrm{Fe}(\mathrm{III}) & \rightarrow \mathrm{Cu}(\mathrm{II})+\mathrm{Fe}(\mathrm{II}) & \{E=0.618 \mathrm{~V}(0.77-0.152)\} \\
\mathrm{Fe}(\mathrm{II})+3 \text { phen } & \rightarrow\left[\mathrm{Fe}(\text { phen })_{3}\right]^{2+} & \log K=38.11
\end{aligned}
$$

Scheme 3. Redox shuttle mechanism of copper(II) ions for cysteine iron(III) electron transfer.

disproportionation by a margin of $10^{6}$ which further get enhanced to $10^{16.57}$ in presence of phen, as the iron redox potential in presence of phen increases to $1.14 \mathrm{~V}$ from its aqueous state potential of $0.77 \mathrm{~V} v s$. NHE. ${ }^{29}$ Thus viability of redox potentials allow copper(II) reduction to copper(I) by cysteine and a quite favourable re-oxidation of copper(I) to copper(II) by iron(III) in presence of phen befitting its role as redox shuttle.

\section{Kinetic Studies}

Inspired from the results, we attempted to further investigate the kinetic profile of reaction by examining the effect of reactant concentration and temperature. The kinetic investigation for both the cases was carried by monitoring the absorbance as a function of time at the respective $\lambda_{\max }$ of resulting iron(II) complexes $\left[\mathrm{FeL}_{3}\right]^{2+}$ Order with respect to $\left[\mathrm{FeL}_{3}\right]^{3+}(\mathrm{L}=$ phen, bipy $)$ and cysteine were determined by initial rates method. Order determination studies with respect to all the reactants under pseudo order conditions revealed an order equal to 1 for both the iron(III) (Figure 8) and cysteine. Order with respect to ligand however could not be determined under the pseudo first order condition, as limiting the ligand concentration posed some thermodynamic as well as kinetic restrictions due to poor complexation.

The order determination studies reveal pseudosecond order kinetics for both the cases with ligands always in excess. The kinetic barrier of the reaction was quantified from temperature dependent kinetic studies. (Figure 9). The activation energy $\left(E_{\mathrm{a}}\right)$ for the reaction was worked out using Arrhenius equation by monitoring

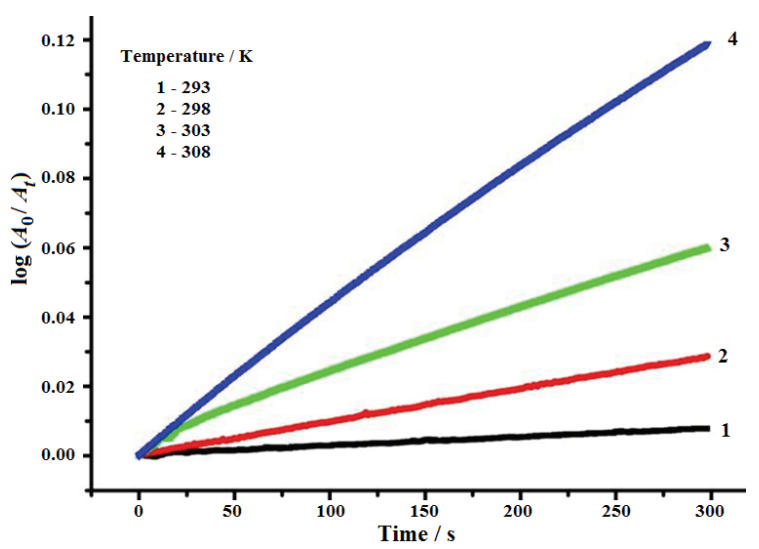

Figure 9. Arrehenius plot of $\left[\mathrm{Fe}(\mathrm{phen})_{3}\right]^{2+}$ cysteine electron transfer kinetics at different temperatures. 
Table 2. Kinetic descriptors of iron(III) cysteine redox reaction in presence of phen and bipy ligands

\begin{tabular}{cccccc}
\hline \multirow{2}{*}{ No. } & \multirow{2}{*}{ Ligand } & \multicolumn{2}{c}{ without $\mathrm{Cu}(\mathrm{II})$} & \multicolumn{2}{c}{ with $\mathrm{Cu}(\mathrm{II})$} \\
\cline { 3 - 6 } & & $E_{\mathrm{a}}^{(\mathrm{a})}$ & $k^{(\mathrm{b})}$ & $E_{\mathrm{a}}^{(\mathrm{a})}$ & $k^{(\mathrm{b})}$ \\
\hline 1 & phen & 47.84 & $6.33 \times 10^{-4}$ & 8.76 & $3.71 \times 10^{-4}$ \\
2 & bipy & 67.21 & $4.73 \times 10^{-4}$ & 17.55 & $1.24 \times 10^{-3}$ \\
\hline
\end{tabular}

(a) Activation energy / $\mathrm{kJ} \mathrm{mol}^{-1}$.

(b) Rate constant at $298 \mathrm{~K}$.

the reaction kinetics at four different temperatures. The activation energies and the rate constants calculated for iron(III) cysteine redox reaction in presence of phen and bipy ligands are mentioned in Table 2 .

\section{CONCLUSION}

This work describes the comparative effect of ligands on the thermo-kinetic behavior of a biologically significant cysteine iron(III) electron transfer. The ligands were found to speed up the redox reaction in proportion to their ability of stabilizing iron(II) in their complexes. The catalytic influence of copper(II) ions as a redox shuttle in the reaction was established from kinetic studies. The differential ability of two closely related $N, N$ bidentate ligands (phen, bipy) towards this reaction was highlighted and corroborated with their structural preorganization using theoretical calculations. The current study was a part of our efforts aimed at the exploration and design of ligand systems capable of blocking the undesired bio-redox reactions. Further efforts are underway towards synthesizing library of ligands with the possible application in prevention of oxidative stress by iron(III) oxidations.

\section{REFERENCES}

1. C. A. Reed, in: The Biological Chemistry of Iron., ed. H. B. Dunford, D. Dolphin, K. M. Raymond, L. Sieker, and D. Reidel, Boston, 1985, pp. 25-42.

2. M. H. Bridge, E. Williams, M. E. G. Lyons, K. F. Tipton, and W. Linert, Biochim. Biophys. Acta 1690 (2004) 77-84.

3. A. Childs, C. Jacobs, T. Kaminski, B. Halliwell, and C. Leeuwenburgh, Free Radic. Biol. Med. 31 (2001) 745-753.

4. W. H. Aust Koppenol, Oxidative Damage and Repair: Chemical,
Biological and Medical Aspects, Pergamon Press, 1991, pp. 802807.

5. R. Banerjee, J. Biol. Chem. 287 (2012) 4397-4402.

6. X. Wang and D. M. Stanbury, Inorg. Chem. 47 (2008) 1224 1236.

7. A. Bhattacharyya, E. Stavitski, J. Dvorak, and C. E. Martinez, Geochim. Cosmochim. Acta 122 (2013) 89-100.

8. K. T. Lemma and L. I. Elding, Inorg. Chem. 39 (2000) 1728 1734.

9. R. Doong and B. Schink, Environ. Sci. Technol. 36 (2002) 2939 2945.

10. E. P. Tchesnokov, S. M. Wilbanks, and G. N. L. Jameson, Biochemistry 51 (2012) 257-264.

11. H. Song, A. S. Her, F. Raso, Z. Zhen, Y. Huo, and P. Liu, Org. Lett. 16 (2014) 2122-2125.

12. R. J. Mailloux, X. Jin, and W. G.Willmore, Redox Biol. 2 (2014) 123-139.

13. M. A. Rizvi, R. Maqsood, and B. U. Khan, J. Chem. Educ. 88 (2011) 220-222.

14. M. A. Rizvi, N. Teshima, and G. M. Peerzada, Croat. Chem. Actahttp://dx.doi.org/10.5562/cca2167 86 (2013) 345-350.

15. M. Altun, E. Edstrom, E. Spooner, A. Flores-Moralez, and E. Bergman, Muscle Nerve 36 (2007) 223-233.

16. F. Zhong, G. P. Lisi, D. P. Collins, J. H. Dawson, and E. V. Pletneva, PNAS 111 (2014) E306-315.

17. N.Teshima, H. Katsumata, and T. Kawashima, Anal. Sci. 16 (2000) 901-911.

18. D. J. Kosman, Coord. Chem. Rev. 257 (2013) 210-217.

19. N. Teshima and T. Kawashima, Bull. Chem. Sco. Jpn. 69 (1996) 1975-1979.

20. D. Naka, D. Kim, R. F. Carbonaro, and T. J. Strathmann, Environ. Toxicol. Chem. 27 (2008) 1257-1266.

21. S. R. Maqsood, N. Islam, S. Bashir, B. U. Khan, and A. H. Pandit, J. Coord. Chem. 66 (2013) 2308-2315.

22. R. D. Hancock and A. E. Martell, Chem. Rev. 89 (1989) 1875 1914.

23. A. J Bard, R. Pearson, and J. Jordan, Standard Potentials in Aqueous Solutions, Marcell Deckker, New York, 1985.

24. L.Pecci, G. Montefoschi, G. Musci, and D. Cavallini, Amino Acids 13 (1997) 355-367.

25. J. Wei, N. Teshima, S. Ohno, and T. Skai, Anal. Sci. 19 (2003) 731-736.

26. N. Teshima, H. Katsumata, M. Kurihara, T. Skai, and T. Kawashima, Talanta 50 (1999) 41-47.

27. D. C. Harris, Quantitative Chemical Analysis, $8^{\text {th }}$ Edn., W.H. Freeman and Company, New York, 2010, Appendix AP21 and Appendix I.

28. D. C. Harris, Quantitative Chemical Analysis, $8^{\text {th }}$ Edn., W. H. Freeman and Company, New York, 2010, p 298.

29. R. L. David, Handbook of Chemistry and Physics, $86^{\text {th }}$ Edn., CRC Press Taylor and Francis, New York, 2005, p8.

30. D. F. Shriver, P. W. Atkins, T. L. Overton, J. P. Rourke, M. T. Weller, and F. A. Armstrong, Inorganic Chemistry, $4^{\text {th }}$ Edn., Oxford University Press, New Delhi , 2006, pp 298-302. 